Gut, 1989, 30, 26-29

\title{
Orocaecal transit time in health and in thyroid disease
}

\author{
M V TOBIN, R A FISKEN, R T DIGGORY, A I MORRIS, \\ AND I T GILMORE \\ From the Gastroenterology Unit, Royal Liverpool Hospital, Liverpool
}

\begin{abstract}
SUMmARY Altered bowel habit commonly occurs in thyroid disease. We measured orocaecal transit in healthy volunteers and in hyperthyroid and hypothyroid patients before and after treatment, using the lactulose hydrogen breath test incorporating a standard liquid meal to obtain a more physiological assessment. Mean transit time in 12 control subjects was 85 (8) minutes (mean (SE)) (mean coefficient of variation between replicate studies, $8 \cdot 6 \%(3 \%)$ ). In eighteen hyperthyroid patients transit was more rapid at $49(4)$ minutes $(p<0 \cdot 01)$. Ten hypothyroid patients had a transit time similar to controls at 91 (9) minutes. Transit time returned to normal in thyrotoxic patients after treatment but in eight hypothyroid patients retested, it remained unchanged. Our findings suggest that (a) the inclusion of a liquid meal provides a reproducible method of measuring orocaecal transit using the lactulose hydrogen breath test, (b) rapid small bowel transit in thyrotoxicosis may be one factor in the diarrhoea which is a feature of the disease and (c) if altered gut transit is the cause of sluggish bowel habit in hypothyroidism, delay in the colon, and not small bowel, is likely to be responsible.
\end{abstract}

Gastrointestinal disturbances are common in thyroid disease and the effect of thyroid hormones on the gastrointestinal tract has long been recognised. ${ }^{1-3}$ Apart from changes in appetite, altered bowel habit is the most frequently reported gastrointestinal symptom. ${ }^{4}$ Hyperthyroid patients may complain of diarrhoea $^{5-8}$ and constipation is a well recognised feature of myxoedema. ${ }^{9}$

The exact relationship between symptoms of altered bowel habit and changes in gut motility and transit time is, however, unclear. Diarrhoea is present in less than $20 \%$ of hyperthyroid patients ${ }^{210}$ despite rapid orocaecal transit in over $90 \%^{11}$ and it may even occur in hypothyroidism where gastrointestinal motor activity is usually decreased. ${ }^{11}{ }^{12}$ In hyperthyroidism, there is poor correlation between transit time and bowel habit in individual patients ${ }^{10}$ where other additional factors including abnormal gastric, ${ }^{6{ }^{1314}}$ pancreatic, ${ }^{15}$ and bile acid ${ }^{16}$ secretion and jejunal mucosal abnormalities ${ }^{x}$ have been reported.

Techniques for measuring pulmonary hydrogen excretion after ingestion of a non-absorbable carbohydrate $^{17}$ allow a more physiological assessment of small bowel transit. Hitherto, this has been measured

Address for correspondence: Dr I T Gilmore, Gastroenterology Unit, Royal Liverpool Hospital, Liverpool L7 8XP.

Received for publication 1 July 1988. using high density and physiologically inert barium sulphate which has resulted in a very broad range of values for normal subjects ${ }^{18}$ and poor reproducibility in a given subject. ${ }^{19}$

Shafer et al using lactulose alone, reported rapid orocaecal transit in 10 hyperthyroid patients, six of whom, when rendered hypothyroid, had a transit time similar to 42 healthy controls..$^{20}$ Nevertheless, they concluded that gastrointestinal transit increases in hypothyroidism and that this prolongation may contribute to the constipation seen in the disorder.

By combining lactulose with a liquid meal, ${ }^{21}$ we investigated the possibility that changes in small bowel transit are a feature of hyperthyroidism and primary hypothyroidism and that altered bowel habit correlates with such changes. We first established the reproducibility of the test by carrying out duplicate studies in normal subjects.

\section{Methods}

PATIENTS

Studies were carried out in the following three groups of subjects: Twelve healthy volunteers (eight women and four men; aged 23-31 years, mean 27). All had duplicate studies done at least four weeks apart; eighteen patients with hyperthyroidism (13 women 
and five men; aged 28-73 year, mean 51). Clinical features were present for at least three months and all had biochemical confirmation. Fourteen had a repeat study at least three months after being rendered clinically and biochemically euthyroid. (Eleven were treated with radioiodine and three with carbimazole); ten patients with primary hypothyroidism (seven women and three men; aged 35-75 years, mean 60). All were symptomatic for at least three months and hypothyroidism was confirmed biochemically. Eight had a repeat study when euthyroid for at least three months.

All subjects were studied after an overnight fast having been instructed to avoid foods likely to generate hydrogen for the 24 hours before the test. None had received antibiotics for at least three months and they were requested not to smoke on the morning of the test. All subjects gave written informed consent.

MEA I.

The homogenised meal ${ }^{21}$ consisted of glucose $40 \mathrm{~g}$, Casilan $15 \mathrm{~g}$ (Farley Health Products Ltd, Plymouth, $\mathrm{UK}$ ), and corn oil $18 \mathrm{~g}$ made up to $270 \mathrm{ml}$ with water to which was added lactulose $30 \mathrm{~g}$ (Duphalac, Duphar Laboratories Ltd, Southampton, UK, $45 \mathrm{ml}$ ).

Collection and analysis of samples were done according to standard techniques. ${ }^{.23}$ Orocaecal transit time was defined as the time elapsing between ingestion of the meal and the first definite and
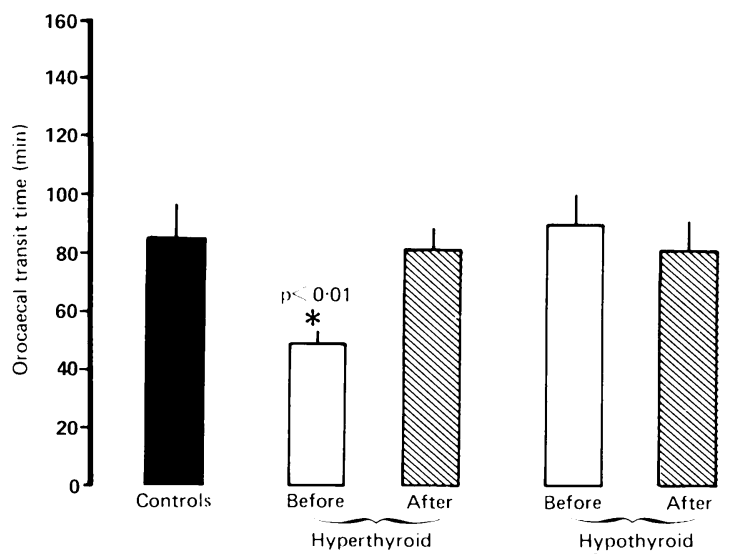

Fig. 1 Orocaecal transit time in 12 healthy subjects studied in duplicate, in 18 hyperthyroid patients studied before and 14 after treatment and in 10 hypothyroid patients before treatment and in eight when rendered euthyroid. Bars represent the mean $(S E)$ for each group. ${ }^{*}$ With respect to all other groups and calculated using Mann-Whitney U test for unpaired data and Wilcoxon's signed rank test for paired studies. sustained rise in breath hydrogen. In all but three studies, this was equivalent to a sustained rise of at least $10 \mathrm{ppm}$ above the baseline value. In three studies where the basal hydrogen levels were less than five and the rise was less than $10 \mathrm{ppm}$, we accepted a doubling of the basal value as the time of entry into caecum..$^{24}$

Differences between mean values were tested using nonparametric tests: the Wilcoxon's signedrank test for paired studies and the Mann-Whitney $U$ test for unpaired studies.

\section{Results}

TRANSIT MEASUREMENTS AND

REPRODUCIBILITY IN NORMAL SUBJECTS

Reproducibility studies on normal subjects showed an orocaecal transit time of 87 (12) minutes (mean (SE)) when first studied and 84 (12) minutes four weeks later (Fig. 1). The mean variation in transit, expressed as the coefficient of variation, was $8.6 \%$ $(3 \cdot 0 \%$ ) (range $0-28 \%$ ) (Fig. 2).

TRANSIT MEASUREMENTS IN PATIENTS WITH HYPERTHYROIDISM AND HYPOTHYROIDISM Hyperthyroid patients had a transit time of 49 (4) minutes which was significantly faster than control subjects $(\mathrm{p}<0 \cdot 01)$ (Fig. 1). Transit time increased in all hyperthyroid subjects after treatment (Fig. 3) and the mean transit when euthyroid (82 (7) minutes) was similar to controls (Fig. 1). In contrast, hypothyroid

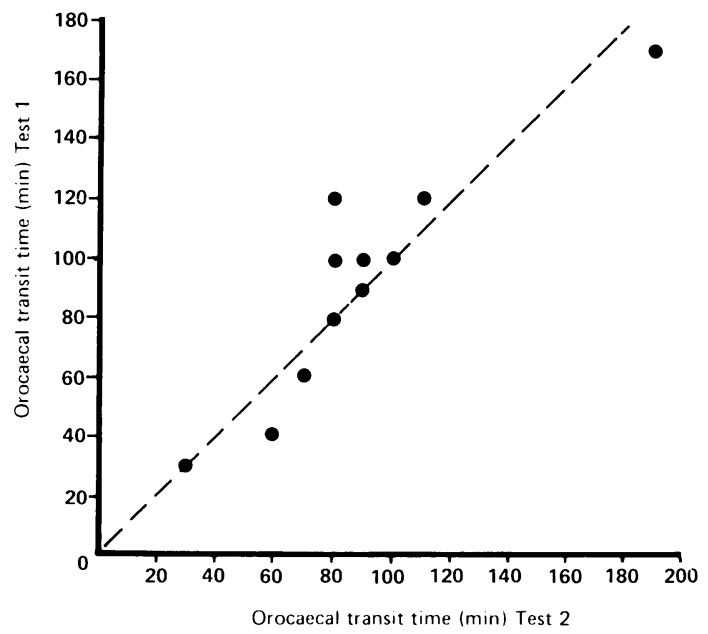

Fig. 2 Reproducibility of duplicate measurements of orocaecal transit time in 12 healthy subjects. The diagonal line indicates the relationship that would exist if duplicate measurements were identical. Two subjects shared a similar transit time in both studies. 


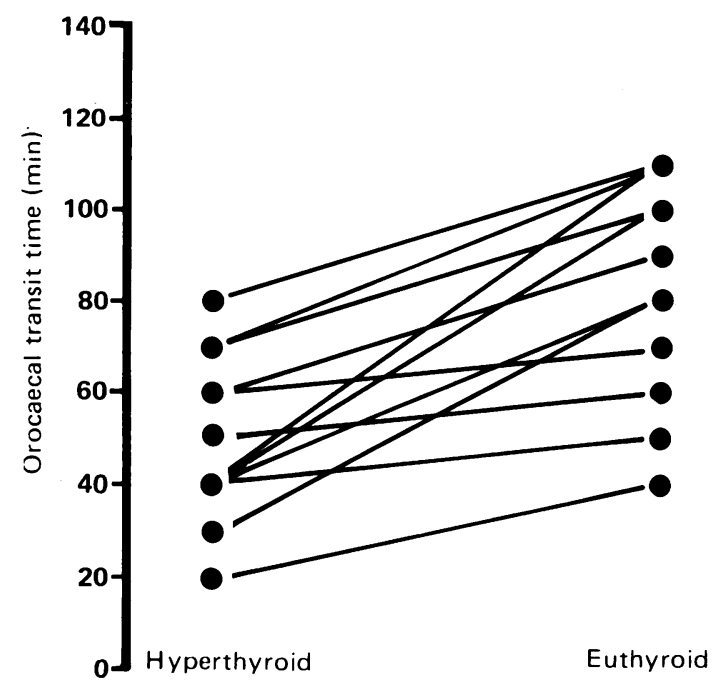

Fig. 3 Orocaecal transit time in 14 hyperthyroid patients before treatment and when euthyroid for at least three months. Transit time increased in all patients.

patients had a normal transit time before treatment (91 (9) minutes) which did not change significantly when rendered euthyroid (Fig. 1).

\section{Discussion}

Gastrointestinal disturbances are well recognised in thyroid disease but their pathophysiology is incompletely understood. ${ }^{425}$ In hyperthyroidism, excessive fat intake as a result of hyperphagia has been reported to largely contribute to the diarrhoea and steatorrhoea. ${ }^{26}$ Results of gastric ${ }^{61314}$ and pancreatic ${ }^{1516}$ exocrine secretion have yielded conflicting results as have bile acid output studies. ${ }^{15}{ }^{16}$ Histological abnormalities have been reported in small bowel biopsies of hyperthyroid ${ }^{8}$ and hypothyroid" man.

It is, however, motor abnormalities, resulting in altered intestinal transit, that have been more widely accepted as an explanation for the disturbed bowel habit seen in thyroid disease. ${ }^{102027}$ This is based primarily on studies of small bowel transit using barium and, although abnormally rapid transit is seen in the majority of patients, ${ }^{102728}$ the use of a metabolically inert meal and the lack of any correlation between transit time and bowel habit in individual patients casts some doubt on any causal relationship between rapid transit and the presence of diarrhoea in hyperthyroidism. Many reports of ileus ${ }^{29}$ pseudoobstruction, ${ }^{30}$ and myxoedema megacolon ${ }^{3132}$ in hypothyroidism have been attributed to slowed bowel motility but diarrhoea and malabsorption have been reported even in the presence of hypomotility. ${ }^{12}$

The use of a physiological meal to determine orocaecal transit is likely to approximate more closely to normal intestinal transit of food. We confirmed the reproducibility of the test in healthy subjects and, indeed, the mean transit time was similar to that reported by La Brooy et al using a slightly smaller dose of lactulose in an identical meal. ${ }^{21}$ Our results, showing rapid small bowel transit in patients with hyperthyroidism, are in agreement with radiological studies ${ }^{102728}$ and with the only previously reported non-radiological study using lactulose alone. ${ }^{20}$ Despite this, only three of our patients had diarrhoea and all three had transit times of greater than 60 minutes before treatment. Hypothyroid patients had a transit time which did not differ from control subjects and changed little after treatment. Only one patient had constipation, which did not resolve after treatment with thyroxine, in spite of a transit time of $\mathbf{7 0}$ minutes before and after treatment.

Our finding of a normal transit time after treatment of thyrotoxicosis contrasts with that of Shafer $e t a l^{20}$ who found the abnormally rapid transit time persisted. Patients in that study who became hypothyroid had a normal transit time, as did our patients with primary hypothyroidism, and so their conclusion that a prolongation of orocaecal transit time may contribute to the constipation of myxoedema does not seem justified. Our results provide some evidence that small bowel hypermotility may be one factor in the diarrhoea and steatorrhoea found in hyperthyroidism. The normal small bowel transit in patients with hypothyroidism, however, suggests that if intestinal hypomotility is the cause of constipation in this condition, delayed colonic transit alone is likely to be responsible.

Previously published in abstract form: Gut 1986; 27: A1270.

\section{References}

1 Verbrycke JR. Marked gastrointestinal hyperthyroidism. JAMA 1931; 97: 513-5.

2 Scarf M. Gastrointestinal manifestations of hyperthyroidism. J Lab Clin Med 1936; 21 : 1253-8.

3 Chapman EM, Maloof F. Bizarre clinical manifestations of hyperthyroidism. N Engl J Med 1956; 254: 1-5.

4 Middleton WRJ, Morrow AW. Thyroid hormones and the gut. Gut 1971; 12: 172-7.

5 Middleton WRJ. Small intestinal structure and function in hyperthyroidism. Sydney: MD thesis, 1969.

6 Siurala M, Julkunen H, Lamberg BA. Gastrointestinal tract in hyperthyroidism before and after treatment. Scand J Gastroenterol 1966; 1: 79-85.

7 Middleton WRJ, Thompson GR. Steatorrhoea in hyperthyroidism. Gut 1968; 9: 725-6. 
8 Hellesen C, Friis T, Larson E, Pock-Steen OC. Small intestinal histology, radiology and absorption in hyperthyroidism. Scand J Gastroenterol 1969; 4: 169-75.

9 Duret RL, Bastenie PA. Intestinal disorders in hypothyroidism. Clinical and manometric study. Am J Dig Dis 1971; 16: 723-7.

10 Shirer JW. Hypermotility of the gastrointestinal tract in hyperthyroidism. Am J Med Sci 1933; 186: 73-8.

11 Siurala M, Varis K, Lamberg BA. Intestinal absorption and autoimmunity in endocrine disorders. Acta Med Scand 1968; 184: 53-64.

12 Kelley ML, Stewart JM. Myxoedema and intestinal malabsorption (nontropical sprue?) with severe hypomotility of the gastrointestinal tract. Am J Dig Dis 1964; 9: 79-86.

13 Dotevall G, Walan A. Gastric secretion of acid and intrinsic factor in patients with hyper- and hypothyroidism. Acta Med Scand 1969; 186: 529-33.

14 Wiersinga WM, Touber JL. The relationship between gastrin, gastric acid and thyroid function disorders. Scand J Gastroenterol [suppl] 1978; 49: 192.

15 Wiley ZD, Lavigne ME, Liu KM, MacGregor IL. The effect of hyperthyroidism on gastric emptying rates and pancreatic exocrine and biliary secretion in man. Am J Dig Dis 1978; 23: 1003-8.

16 Miller LJ, Owyang C, Malagelada J-R, Gorman CA, Go VLW. Gastric, pancreatic and biliary responses to meals in hyperthyroidism. Gut 1980; 21: 695-700.

17 Bond $\mathrm{JH}$, Levitt MD. Investigation of small bowel transit time in man utilizing pulmonary hydrogen measurements. J Lab Clin Med 1975; 85: 546-55.

$18 \mathrm{Kim}$ SK. Small intestine transit time in the normal small bowel study. Am J Roentgenol 1968; 104: 522-4.

19 Lonnerblad L. Transit time through small intestine. Roentgenologic study on normal variability. Acta Radiol [Suppl] Stockh 1951: 88.

20 Shafer RB, Prentiss RA, Bond JH. Gastrointestinal transit in thyroid disease. Gastroenterology 1984; 86: 852-5.
21 La Brooy SJ, Male P-J, Beavis AK, Misiewicz JJ. Assessment of the reproducibility of the lactulose hydrogen breath test as a measure of mouth to caecum transit time. Gut 1983; 24: 893-6.

22 Metz G, Gassull MA, Leeds AR, Blendis AM, Jenkins DJA. A simple method of measuring breath hydrogen in carbohydrate malabsorption by end-expiratory sampling. Clin Sci Mol Med 1976; 50: 237-40.

23 Corbett CL, Thomas S, Read NW, Hobson N, Bergman I, Holdsworth CD. Electrochemical detector for breath hydrogen determination: measurement of small bowel transit time in normal subjects and patients with the irritable bowel syndrome. Gut 1981; 22: 836-40.

24 Read NW. Al-Janabi MN, Bates TE, et al. Interpretation of the breath hydrogen profile obtained after ingesting a solid meal containing unabsorbable carbohydrate. Gut 1985; 26: 834-42.

25 Miller LJ, Gorman CA, Go VLW. Gut-thyroid interrelationships. Gastroenterology 1978; 75: 901-11.

26 Thomas FB, Caldwell JH, Greenberger NJ. Steatorrhoea in thyrotoxicosis. Relationship to hypermotility and excessive dietary fat. Ann Intern Med 1973; 78: 66975.

27 Brown RB, Pendergrass EP, Burdick ED. Hypermotility of the gastrointestinal tract in hyperthyroidism. Surg Gynecol Obstet 1941; 73: 766-83.

28 Neporent MI, Spesivtseva VG. Motor function of gastrointestinal tract before and after ${ }^{131} I$ therapy in patients with thyrotoxicosis. Fed Proc 1963; 22 [suppl]: T1177-80.

29 Boruchow IB, Miller LD, Fitts WT. Paralytic ileus in myxedema. Arch Surg 1966; 92: 960-3.

30 Abbasi AA, Douglass RC, Bissell GW, Chen Y. Myxedema ileus. A form of intestinal pseudoobstruction. JAMA 1975; 234: 181-3.

31 Hohl RD, Nixon RK. Myxedema ileus. Arch Intern Med 1965; 115: 145-50.

32 Wells I, Smith B, Hinton M. Acute ileus in myxoedema. Br Med J 1977; i: 211-2. 